\title{
Hypothermic circulatory arrest is not a risk factor for neurologic morbidity in aortic surgery: A propensity score analysis
}

Takashi Kunihara, MD, PhD, ${ }^{\text {a* }}$ Timo Grün, MD, ${ }^{a}$ Diana Aicher, MD, ${ }^{a}$ Frank Langer, MD, ${ }^{\text {a }}$ Oliver Adam, MD, ${ }^{a}$ Olaf Wendler, MD, PhD, ${ }^{\text {a }}$ Yasuaki Saijo, MD, PhD, ${ }^{b}$ and Hans-Joachim Schäfers, MD, PhD

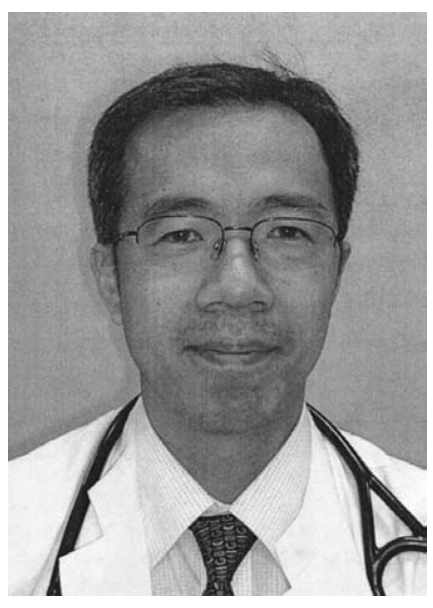

Dr Kunihara

\begin{abstract}
From the Department of Thoracic and Cardiovascular Surgery, ${ }^{\text {a }}$ University Hospital Homburg, Homburg, Germany, and the Department of Public Health, ${ }^{\mathrm{b}}$ Hokkaido University Graduate School of Medicine, Sapporo, Japan.

Received for publication Feb 6, 2005; revisions received March 22, 2005; accepted for publication March 31, 2005.

Address for reprints: Hans-Joachim Schäfers, MD, PhD, Department of Thoracic and Cardiovascular Surgery University Hospital Homburg, 66424 Homburg, Germany (E-mail: chhjsc@uniklinik-saarland.de).

*Dr Kunihara is currently affiliated with the Department of Cardiovascular Surgery, Hokkaido University Hospital, Sapporo, Japan 060-8648.

J Thorac Cardiovasc Surg 2005;130:712-8

$0022-5223 / \$ 30.00$
\end{abstract}

Copyright (C) 2005 by The American Association for Thoracic Surgery

doi:10.1016/j.jtcvs.2005.03.043
Objective: Hypothermic circulatory arrest has been an important tool in aortic arch surgery, even though its use has recently been discussed controversially. We sought to clarify the role of hypothermic circulatory arrest as a risk factor for mortality and neurologic morbidity in aortic surgery by using a propensity score-matching analysis.

Methods: Five hundred eleven patients $(60 \pm 13$ years, 349 male patients $)$ who underwent replacement of the ascending aorta with $(\mathrm{n}=273)$ or without $(\mathrm{n}=238)$ arch involvement were analyzed by means of multivariate analysis. Using propensity score matching, we identified comparable patient groups: $\mathrm{HCA}(+)$ group and $\mathrm{HCA}(-)$ group $(\mathrm{n}=110$ each). For aortic arch replacement, hypothermic circulatory arrest was used with a mean duration of $14 \pm 9$ minutes: $12 \pm 7$ minutes or 26 \pm 8 minutes for partial or total arch replacement, respectively.

Results: In the entire cohort multivariate analysis identified acute dissection and duration of cardiopulmonary bypass as significant predictors for hospital death. Predictors for stroke were acute dissection, diabetes mellitus, peripheral arterial disease, and concomitant mitral valve surgery, and predictors for temporary neurologic dysfunction were peripheral arterial disease and age. After propensity score matching, the incidence of death $(\mathrm{HCA}[+]: 0.9 \%$ vs $\mathrm{HCA}[-]: 2.7 \%)$, stroke $(0 \%$ vs $1.8 \%$, respectively), and temporary neurologic dysfunction (15.5\% vs $13.6 \%$, respectively) was comparable between the 2 groups. Multivariate analysis identified age, diabetes mellitus, peripheral arterial disease, and concomitant coronary artery bypass grafting as the independent risk factors for temporary neurologic dysfunction.

Conclusions: In a standard clinical setting (hypothermic circulatory arrest of $<30$ minutes and nasopharyngeal temperature of $<20^{\circ} \mathrm{C}$ ), hypothermic circulatory arrest constitutes no significant risk for mortality or neurologic morbidity and thus appears clinically safe. Patient-related risk factors primarily determine clinical outcome.

$\mathrm{N}$ eurologic morbidity is known to occur after hypothermic circulatory arrest (HCA) and can roughly be classified into 2 types: permanent neurologic deficit or stroke and temporary neurologic dysfunction (TND). ${ }^{1}$ The former is thought to be primarily the consequence of embolic events, and the latter has been related to suboptimal brain protection during HCA (ie, cerebral hypoxia). TND has been found to correlate with the duration of $\mathrm{HCA}^{2}{ }^{2}$ Some form of antegrade cerebral perfusion during arch repair has increasingly been advocated to minimize the incidence of both transient and permanent neurologic impairment. ${ }^{3-5}$ Antegrade perfusion, however, might increase the incidence of embolism, and it clearly prolongs the time required for arch replacement or repair. ${ }^{3-5}$ 
TABLE 1. Baseline characteristics

\begin{tabular}{|c|c|c|c|c|c|c|c|c|}
\hline & \multicolumn{4}{|c|}{ Entire study sample } & \multicolumn{4}{|c|}{ Propensity-matched pairs } \\
\hline & Overall & HCA(-) & $\mathrm{HCA}(+)$ & $P$ value & Overall & HCA(-) & $\mathrm{HCA}(+)$ & $P$ value \\
\hline $\mathrm{N}$ & 511 & 238 & 273 & & 220 & 110 & 110 & \\
\hline Sex (male) & $349(68 \%)$ & $185(78 \%)$ & $164(60 \%)$ & $<.0001$ & $150(68 \%)$ & $74(67 \%)$ & $76(69 \%)$ & .7722 \\
\hline Age (y) & $60 \pm 13$ & $57 \pm 13$ & $62 \pm 12$ & $<.0001$ & $63 \pm 11$ & $62 \pm 11$ & $63 \pm 11$ & .7277 \\
\hline $\begin{array}{l}\text { Emergency operation for acute } \\
\text { dissection }\end{array}$ & $105(21 \%)$ & $0(0 \%)$ & $105(38 \%)$ & $<.0001$ & 0 & 0 & 0 & NA \\
\hline Smoking history & $168(33 \%)$ & $87(37 \%)$ & $81(30 \%)$ & .0984 & $80(36 \%)$ & $36(33 \%)$ & $44(40 \%)$ & .2622 \\
\hline Hypertension & $356(70 \%)$ & $156(66 \%)$ & $200(73 \%)$ & .0585 & $166(75 \%)$ & $82(75 \%)$ & $84(76 \%)$ & .7540 \\
\hline $\begin{array}{l}\text { Hyperlipidemia (cholesterol } \\
>200 \mathrm{mg} / \mathrm{dL} \text { ) }\end{array}$ & $138(27 \%)$ & $68(29 \%)$ & $70(26 \%)$ & .4567 & $72(33 \%)$ & $40(36 \%)$ & $32(29 \%)$ & .2504 \\
\hline Diabetes mellitus & $53(10 \%)$ & $21(9 \%)$ & $32(12 \%)$ & .2838 & $25(11 \%)$ & $12(11 \%)$ & $13(12 \%)$ & .8318 \\
\hline Ischemic heart disease & $196(38 \%)$ & $91(38 \%)$ & $105(38 \%)$ & .9582 & $99(45 \%)$ & $56(51 \%)$ & $43(39 \%)$ & .0781 \\
\hline Carotid artery stenosis ( $>50 \%)$ & $10(3 \%)$ & $4(2 \%)$ & $6(3 \%)$ & .7744 & $3(2 \%)$ & $2(2 \%)$ & $1(1 \%)$ & .6185 \\
\hline Peripheral arterial disease & $30(6 \%)$ & $14(6 \%)$ & $16(6 \%)$ & .9918 & $19(9 \%)$ & $11(10 \%)$ & $8(7 \%)$ & .4715 \\
\hline Cerebrovascular disease & $50(10 \%)$ & $17(7 \%)$ & $33(12 \%)$ & .0605 & $28(13 \%)$ & $12(11 \%)$ & $16(15 \%)$ & .4184 \\
\hline
\end{tabular}

$H C A$, Hypothermic circulatory arrest; $N A$, not applicable.

Stroke ${ }^{6}$ and TND, ${ }^{7}$ on the other hand, are known to occur after conventional cardiac surgery with or without cardiopulmonary bypass $(\mathrm{CPB})$. It has been speculated that $\mathrm{CPB}$, manipulation of an atheromatous ascending aorta, ${ }^{8}$ air embolism, ${ }^{9}$ or carotid artery stenosis-atherosclerosis ${ }^{10}$ are responsible for these neurologic complications. ${ }^{6}$

We speculate that a limited period of HCA $(<30$ minutes) might not be a relevant causative risk factor for neurologic morbidity in aortic surgery. In this retrospective clinical investigation, we sought to clarify the relative roles of HCA versus patient-related risk factors for mortality or neurologic morbidity, such as stroke and TND, in aortic surgery. To generate comparable groups, we studied patients who underwent arch replacement with HCA and compared them with patients who underwent ascending aortic replacement on continuous CPB. In addition, we used a propensity score-matching analysis to minimize selection bias between the 2 groups.

\section{Materials and Methods \\ Patient Profile}

A total of 511 patients who underwent replacement of the ascending aorta with $(\mathrm{n}=273)$ or without $(\mathrm{n}=238)$ arch involvement were entered into this retrospective study. The patients had been treated consecutively for proximal aortic disease (aneurysm or dissection) at the University Hospital Homburg between 1995 and 2004. Individuals who were treated with replacement of a calcified nondilated or dissected aorta were excluded. All documentation in the patient charts served as a database. There were 349 male and 162 female patients, and patient age ranged from 17 to 83 years (mean, $60 \pm 13$ years). Concomitant cardiac operations were necessary in $424(83 \%)$ patients: aortic valve or root repairreplacement in $396(77 \%)$, coronary artery bypass grafting $(\mathrm{CABG})$ in $122(24 \%)$, and mitral valve repair-replacement in 16
(3\%). Emergency operations for acute aortic dissection were performed in 105 (21\%) patients.

The patients were divided into 2 groups according to the use of HCA during the operation: the $\mathrm{HCA}(+)$ group and the $\mathrm{HCA}(-)$ group. In the $\mathrm{HCA}(-)$ group there were significantly more male patients, and patients were younger (Table 1). The incidence of concomitant aortic valve-root operation and arterial perfusion through the femoral artery was less, and there were no emergency operations for acute aortic dissection. Other cardiac risk factors were almost comparable between the groups (Tables 1 and 2).

Initially, the whole patient population was analyzed in multivariate fashion by using logistic regression to determine predictors of death, stroke, and TND.

\section{Matched Risk Factor Analysis}

In view of the marked and significant differences in patient characteristics between the groups, patient matching seemed necessary to evaluate the pure effect of HCA on mortality and postoperative neurologic morbidity. To compensate for the differences in this retrospective nonrandomized study, we used a propensity scorematching analysis.

By using logistic regression, the probability of being assigned to HCA over continuous perfusion was calculated from baseline and perioperative characteristics. Then a $P$ value of less than .20 was defined for selecting variables for entry into the final model. Selected variables were as follows: sex, age, smoking, hypertension, acute dissection, cerebrovascular disease, retrograde arterial perfusion, duration of $\mathrm{CPB}$, and aortic valve-root operation. By using these covariables, a propensity score was calculated for each patient. Finally, each patient who underwent HCA was matched to one patient who underwent no HCA with the closest propensity score. The maximum difference of propensity score for a match was less than .015 . By using this novel technique, comparable patient groups, 110 patients from each group, were identified for 
TABLE 2. Concomitant operations, perfusion data, and postoperative morbidity-mortality

\begin{tabular}{|c|c|c|c|c|c|c|c|c|}
\hline & \multicolumn{4}{|c|}{ Entire study sample } & \multicolumn{4}{|c|}{ Propensity-matched pairs } \\
\hline & Overall & $\mathrm{HCA}(-)$ & HCA(+) & $P$ value & Overall & HCA $(-)$ & $\mathrm{HCA}(+)$ & $P$ value \\
\hline $\mathrm{N}$ & 511 & 238 & 273 & & 220 & 110 & 110 & \\
\hline Concomitant operation & $424(83 \%)$ & $225(95 \%)$ & $199(73 \%)$ & $<.0001$ & $199(90 \%)$ & $100(91 \%)$ & $99(90 \%)$ & .8185 \\
\hline Aortic valve-root operation & $396(77 \%)$ & $221(93 \%)$ & $175(64 \%)$ & $<.0001$ & $192(87 \%)$ & $96(87 \%)$ & $96(87 \%)$ & NA \\
\hline Coronary artery bypass grafting & $122(24 \%)$ & $62(6 \%)$ & $60(22 \%)$ & .2814 & $70(32 \%)$ & $40(36 \%)$ & $30(27 \%)$ & .1478 \\
\hline Mitral valve operation & $16(3 \%)$ & $8(3 \%)$ & $8(3 \%)$ & .7802 & $8(4 \%)$ & $4(4 \%)$ & $4(4 \%)$ & N.A. \\
\hline Retrograde arterial perfusion & $76(15 \%)$ & $3(1 \%)$ & $73(27 \%)$ & $<.0001$ & $5(2 \%)$ & $3(3 \%)$ & $2(2 \%)$ & .6510 \\
\hline Duration of CPB (min) & $125 \pm 52$ & $113 \pm 48$ & $135 \pm 53$ & $<.0001$ & $123 \pm 44$ & $124 \pm 54$ & $123 \pm 32$ & .9199 \\
\hline Duration of $A X C$ (min) & $80 \pm 38$ & $79 \pm 46$ & $80 \pm 31$ & .6663 & $81 \pm 27$ & $81 \pm 28$ & $81 \pm 25$ & .9343 \\
\hline Duration of HCA (min) & & NA & $18 \pm 10$ & NA & & NA & $14 \pm 9$ & NA \\
\hline Re-exploration for bleeding & $44(9 \%)$ & $10(4 \%)$ & $34(12 \%)$ & .0009 & $12(5 \%)$ & $5(4 \%)$ & $7(6 \%)$ & .5534 \\
\hline $\begin{array}{l}\text { Duration of mechanical } \\
\text { ventilation (d) }\end{array}$ & $1.5 \pm 4.6$ & $1.0 \pm 4.4$ & $1.9 \pm 4.7$ & .0237 & $1.0 \pm 1.9$ & $0.8 \pm 2.0$ & $1.1 \pm 1.9$ & .2634 \\
\hline Duration of ICU stay (d) & $3.3 \pm 5.1$ & $2.4 \pm 4.0$ & $4.1 \pm 5.9$ & .0002 & $2.7 \pm 2.6$ & $2.4 \pm 2.2$ & $3.0 \pm 2.9$ & .0583 \\
\hline Hospital death & $32(6.3 \%)$ & $9(3.8 \%)$ & $23(8.4 \%)$ & .0307 & $4(1.8 \%)$ & $3(2.7 \%)$ & $1(0.9 \%)$ & .3129 \\
\hline Stroke & $19(3.7 \%)$ & $6(2.5 \%)$ & $13(4.8 \%)$ & .1817 & $2(0.9 \%)$ & $2(1.8 \%)$ & 0 & .1554 \\
\hline TND & $66(12.9 \%)$ & $22(9.2 \%)$ & $44(16.1 \%)$ & .0208 & $32(14.5 \%)$ & $15(13.6 \%)$ & $17(15.5 \%)$ & .7021 \\
\hline
\end{tabular}

HCA, Hypothermic circulatory arrest; $C P B$, cardiopulmonary bypass; $A X C$, aortic crossclamp; $I C U$, intensive care unit; $T N D$, temporary neurologic dysfunction.

final analysis. Baseline characteristics of propensity-matched pairs were almost identical (Table 1).

\section{Anesthesia and CPB}

All patients received general anesthesia through standard continuous intravenous administration of propofol and sufentanil. No barbiturates or steroids were administered, and cerebral protection included topical cooling of the head with ice during HCA.

A non-heparin-coated circuit (Raumedic; Rehau AG+Co, Rehau, Germany), a roller pump (Stöckert Instrumente $\mathrm{GmbH}$, München, Germany), a membrane oxygenator (Quadrox; Jostra Medizintechnik GmbH and Co KG, Hirrlingen, Germany), and an arterial filter (Quart, $40-\mu \mathrm{m}$ pore size; Jostra Medizintechnik $\mathrm{GmbH}$ and $\mathrm{Co} \mathrm{KG)} \mathrm{were} \mathrm{used} \mathrm{for} \mathrm{CPB.} \mathrm{The} \mathrm{CPB} \mathrm{system} \mathrm{was} \mathrm{set}$ up as a closed system and primed mainly with lactated Ringer solution. A cell saver (C.A.T.S; Fresenius AG, Bad Homburg, Germany) was used for reprocessing of shed blood. Alpha-stat strategy was applied during CPB. Patients undergoing arch replacement were placed in the head-down position during HCA to avoid cerebral embolism.

\section{Operative Technique}

All operations were performed through a median sternotomy. For patients with chronic dissection or stable aneurysm, CPB was established between an ascending aortic cannula and a single venous cannula. For patients with acute dissection, the left femoral artery was used for cannulation until May 2001; after that time, the right axillary artery was used for arterial inflow to minimize the risk of retrograde embolism or malperfusion. During core cooling, the ascending aorta was crossclamped, and blood cardioplegia was administered directly into the coronary ostia. For patients without need of arch replacement, the operations were performed at a rectal temperature of $32^{\circ} \mathrm{C}$ to $33^{\circ} \mathrm{C}$. For patients with arch involvement, proximal procedures (aortic or mitral valve repair-replacement or
CABG) were performed during core cooling. When the nasopharyngeal temperature reached $18^{\circ} \mathrm{C}$ to $20^{\circ} \mathrm{C}$, the patients were placed in the head-down position, and the aortic crossclamp was removed for HCA. Hypothermic arrest was used for partial $(\mathrm{n}=$ $205)$ or total $(n=68)$ arch replacement, and it was combined with a brief period of retrograde cerebral perfusion to flush out atherosclerotic debris in 6 cases. The mean duration of HCA was $15 \pm$ 8 minutes for partial and $28 \pm 10$ minutes for total arch replacement. In 110 patients selected for propensity score matching, the mean duration of HCA was $12 \pm 7$ minutes for partial $(n=92)$ and $26 \pm 8$ minutes for total $(\mathrm{n}=18)$ arch replacement. The lowest nasopharyngeal temperature was $18^{\circ} \mathrm{C} \pm 1{ }^{\circ} \mathrm{C}$. A single anastomosis between the graft and the arch was created for partial arch replacement. When total aortic arch replacement was required, an anastomosis was created between the graft and the descending aorta. The ostia of the 3 arch vessels were connected to the arch prosthesis in an en bloc technique. Gelatin-resorcinformalin glue (Fii, Saint-Just-Malmont, France) was used to reapproximate distal aortic wall layers in patients with acute dissection.

After completion of the arch anastomosis, the prosthesis was cannulated directly, and whole-body circulation resumed in an antegrade fashion. If an axillary arterial cannula had been inserted initially, this was used also for inflow during rewarming.

The remaining procedures were completed during rewarming. After careful deairing, the crossclamp was removed, and the patient was weaned from CPB after sufficient rewarming (rectal temperature, $>34^{\circ} \mathrm{C}$ ). Two mediastinal tubes were placed, and the chest was closed in standard fashion.

\section{Neurologic Outcome}

According to the report by Ergin and associates, ${ }^{1}$ we defined TND as the occurrence of at least one of the following symptoms: postoperative confusion, agitation, delirium, prolonged obtundation, or transient parkinsonism without obvious neurologic deficit. 
TABLE 3. Multivariate logistic regression analysis to identify independent predictors for mortality, stroke, and temporary neurologic dysfunction in the entire study sample

\begin{tabular}{|c|c|c|c|c|c|c|c|c|c|}
\hline & \multicolumn{3}{|c|}{ Hospital death } & \multicolumn{3}{|c|}{ Stroke } & \multicolumn{3}{|c|}{ TND } \\
\hline & $P$ value & $\mathbf{O R}$ & $95 \% \mathrm{Cl}$ & $P$ value & $\mathbf{O R}$ & 95\% Cl & $P$ value & $\mathbf{O R}$ & $95 \% \mathrm{Cl}$ \\
\hline Acute dissection & .0077 & 7.084 & $1.678-29.899$ & $<.0001$ & 25.946 & $5.855-114.979$ & & & \\
\hline Duration of CPB & .0004 & 1.013 & $1.006-1.020$ & & & & & & \\
\hline Diabetes mellitus & & & & .0210 & 4.500 & $1.254-16.147$ & & & \\
\hline Peripheral arterial disease & & & & .0053 & 7.979 & $1.853-34.359$ & .0027 & 4.848 & $1.727-13.604$ \\
\hline Concomitant mitral valve surgery & & & & $<.0001$ & 41.416 & 8.794-195.057 & & & \\
\hline Age & & & & & & & .0221 & 1.068 & $1.010-1.130$ \\
\hline
\end{tabular}

$T N D$, Temporary neurologic dysfunction; $O R$, odds ratio; $C P B$, cardiopulmonary bypass.

Stroke was defined as the presence of transient or permanent focal neurologic deficit that was confirmed by means of computed tomographic scans as new defects.

\section{Statistical Analysis}

All values are expressed as means \pm standard deviation. Statistical analysis was performed with the StatView 5.0 program (SAS Institute Inc, Cary, NC). The Student $t$ test was used for comparison of the continuous variables, and the $\chi^{2}$ test was used for comparison of frequencies between the groups.

\section{Results}

Analysis of the Entire Patient Population

In the entire cohort the mean duration of CPB was significantly longer in the $\mathrm{HCA}(+)$ group than in the $\mathrm{HCA}(-)$ group, and myocardial ischemic time was almost identical. In the $\mathrm{HCA}(+)$ group the incidence of re-exploration for bleeding was significantly higher, and the mean duration of both mechanical ventilation and intensive care unit stay was also significantly longer than in the $\operatorname{HCA}(-)$ group (Table 2).

Postoperative overall hospital mortality was $6.3 \%(3.4 \%$ after elective operations). Postoperative TND was seen in $66(12.9 \%)$ patients, and $19(3.7 \%)$ patients had a stroke.
The incidence of hospital death $(8.4 \%$ vs $3.8 \%, P=.0307)$ and TND (16.1\% vs $9.2 \%, P=.0208)$ was significantly higher in the $\mathrm{HCA}(+)$ group than in the $\mathrm{HCA}(-)$ group. More strokes occurred in the $\mathrm{HCA}(+)$ group (Table 2), but the difference was not significant $(4.8 \%$ vs $2.5 \%, P=$ .1817).

Multivariate logistic regression analysis identified acute dissection and duration of CPB as significant independent predictors for hospital death. Acute dissection, diabetes mellitus, peripheral arterial disease, and concomitant mitral valve surgery were also identified as significant independent predictors for stroke. Peripheral arterial disease and increased age were also identified as significant independent predictors for TND (Table 3).

Emergency operation for acute aortic dissection was a strong risk factor for both mortality and stroke, and all of these patients were included in the $\mathrm{HCA}(+)$ group. Compared with elective procedures, emergency procedures were associated with longer duration of CPB and HCA, mechanical ventilation, and intensive care unit stay. The incidence of re-exploration for bleeding, stroke, and mortality was also significantly higher in patients who underwent emergency operations (Table 4).

TABLE 4. Comparison of perfusion data and postoperative morbidity-mortality between patients who underwent emergency versus elective operations in the entire study population

\begin{tabular}{|c|c|c|c|c|}
\hline & Overall & Acute dissection & Nondissection & $P$ value \\
\hline $\mathrm{N}$ & 511 & $105(21 \%)$ & $406(79 \%)$ & \\
\hline Duration of $\mathrm{CPB}$ (min) & $125 \pm 52$ & $151 \pm 68$ & $118 \pm 45$ & $<.0001$ \\
\hline Duration of $A X C$ (min) & $80 \pm 38$ & $85 \pm 35$ & $78 \pm 39$ & .1252 \\
\hline Duration of HCA (min) & $18 \pm 10$ & $21 \pm 10$ & $16 \pm 10$ & $<.0001$ \\
\hline Re-exploration for bleeding & $44(9 \%)$ & $20(19 \%)$ & $24(6 \%)$ & $<.0001$ \\
\hline Duration of mechanical ventilation (d) & $1.5 \pm 4.6$ & $3.4 \pm 7.2$ & $1.0 \pm 3.5$ & $<.0001$ \\
\hline Duration of ICU stay (d) & $3.3 \pm 5.1$ & $5.7 \pm 8.1$ & $2.7 \pm 3.8$ & $<.0001$ \\
\hline Hospital death & $32(6.3 \%)$ & $18(17.1 \%)$ & $14(3.4 \%)$ & $<.0001$ \\
\hline Stroke & $19(3.7 \%)$ & $11(10.5 \%)$ & $8(2.0 \%)$ & $<.0001$ \\
\hline TND & $66(12.9 \%)$ & $19(18.1 \%)$ & $47(11.6 \%)$ & .0758 \\
\hline
\end{tabular}

$\overline{C P B}$, Cardiopulmonary bypass; $A X C$, aortic crossclamp; $H C A$, hypothermic circulatory arrest; $I C U$, intensive care unit; $T N D$, temporary neurologic dysfunction. 
TABLE 5. Univariate and multivariate logistic regression analysis to identify the independent predictors for temporary neurologic dysfunction in the propensity-matched patients

\begin{tabular}{|c|c|c|c|c|c|c|}
\hline & & \multirow[b]{2}{*}{ Incidence of TND } & \multirow{2}{*}{$\frac{\text { Univariate }}{P \text { value }}$} & \multicolumn{3}{|c|}{ Multivariate } \\
\hline & & & & $P$ value & $\mathbf{O R}$ & $95 \% \mathrm{CI}$ \\
\hline \multirow[t]{2}{*}{ Age (y) } & Yes & $70 \pm 5$ & $<.0001$ & . 0073 & 1.100 & $1.026-1.179$ \\
\hline & No & $61 \pm 11$ & & & & \\
\hline \multirow[t]{2}{*}{ Diabetes mellitus } & Yes & $9 / 25(36 \%)$ & .0039 & .0175 & 3.416 & $1.240-9.411$ \\
\hline & No & $23 / 195(12 \%)$ & & & & \\
\hline \multirow[t]{2}{*}{ Peripheral arterial disease } & Yes & $9 / 19(47 \%)$ & .0003 & .0141 & 3.940 & $1.318-11.777$ \\
\hline & No & 23/201 (11\%) & & & & \\
\hline \multirow[t]{2}{*}{ Concomitant CABG } & Yes & $20 / 70(29 \%)$ & .0001 & .0162 & 2.850 & $1.213-6.696$ \\
\hline & No & $12 / 150(8 \%)$ & & & & \\
\hline
\end{tabular}

$T N D$, Temporary neurologic dysfunction; $O R$, odds ratio; $C A B G$, coronary artery bypass grafting.

\section{Propensity Score-matching Analysis}

In propensity-matched pairs both intraoperative and postoperative data were almost identical between the groups (Table 2). No patients with acute dissection were included in the matched groups. Only one hospital death $(0.9 \%)$ and no strokes developed in the $\mathrm{HCA}(+)$ group, whereas $3(2.7 \%)$ hospital deaths and $2(1.8 \%)$ strokes were observed in the $\mathrm{HCA}(-)$ group. TND was identified in $17(15.5 \%)$ patients in the $\mathrm{HCA}(+)$ group and $15(13.6 \%)$ patients in the $\mathrm{HCA}(-)$ group.

Because operative mortality and the incidence of stroke were too low for statistical analysis, logistic regression analysis was performed to identify predictive factors for TND. Both univariate and multivariate analysis identified age, diabetes mellitus, peripheral arterial disease, and concomitant $\mathrm{CABG}$ as significant independent risk factors for TND (Table 5).

In 110 patients in the $\mathrm{HCA}(+)$ group selected for propensity score matching, the duration of HCA was not a significant independent predictor for TND $(P=.4414$; odds ratio, 1.021; 95\% CI, 0.968-1.077). In 17 patients who had TND, the mean duration of HCA was $16 \pm 10$ minutes, whereas it was $14 \pm 9$ minutes in 93 patients without postoperative TND. This difference was not significant $(P$ $=.4423)$. The proportion of total arch replacement was not significantly different between patients who had TND (1/17 [6\%]) and those who did not (17/93 [18\%], $P=.2039)$.

\section{Discussion}

Although HCA has played a central role in the development of surgical strategies to repair the aortic arch, it has recently been the subject of controversial discussion. Neurologic complications of aortic surgery have gained increasing attention, and some surgeons have believed that stroke and TND were mainly caused by hypoxia as part of HCA. ${ }^{1,2,11-13}$ An increasing number of publications have propagated ${ }^{3-6,11,14,15}$ retrograde or antegrade perfusion to provide additional cerebral blood flow. Most studies, however, were simply based on a retrospective analysis of operations performed in nonrandomized fashion with historical control groups. Therefore selection bias was possible between the study and control groups.

A reasonable control group must be used that includes, apart from circulatory arrest, a comparable prevalence of risk factors for stroke or TND to analyze the true effect of HCA on cerebral function. Embolism of air, calcium, or atherosclerotic debris might result in stroke independent of circulatory arrest. TND might occur without interruption of cerebral blood supply and is a well-recognized complication of major cardiac operations. ${ }^{7}$ Thus there are multiple potential risk factors for neurologic complications, particularly in cardiac surgery. This is emphasized by the fact that the risk of stroke in aortic valve replacement and coronary surgery ranges from about $1.5 \%$ to more than $3 \%,{ }^{16}$ and TND is seen in as many as $34 \%$ to $69 \%$ of patients in the early postoperative phase. ${ }^{17-20}$ Published risk factors for stroke have been identified as age of 70 years or older, diabetes, and previous cerebrovascular accident. ${ }^{21-23}$ Older age also has been found to be a predictor of TND. ${ }^{19}$

The findings in the initial analysis emphasize the important influence of underlying disease on outcome. Emergency operations for acute dissection greatly influenced both hospital mortality and the incidence of stroke. This finding is consistent with other reports, regardless of adjuncts with $\mathrm{HCA}^{2,12,24}$ or antegrade cerebral perfusion, ${ }^{2,3,24}$ perhaps because acute dissection might promote inflammatory cascade ${ }^{25}$ and internal opiate that will be deleterious to ischemia-reperfusion injury in the central nervous system during aortic surgery. A more important reason might be malperfusion of the arch vessels when they are involved with dissection and the true lumen is compressed by the false lumen. ${ }^{26}$

Any investigation focusing on the possible detrimental effects of circulatory arrest must take other potential risk factors into consideration. Because a prospective random- 
ized investigation is difficult to generate, a matched analysis seems a reasonable substitute. To maximize the information content in dealing with heterogeneous patient populations, a propensity score-based matched analysis appears to be a good solution. The study and the control group should include similar diagnosis and comorbidity. To achieve this, we chose patients with ascending aortic replacement without interruption of cerebral blood flow as control subjects.

A propensity score-matching analysis ${ }^{27,28}$ was used to eliminate selection bias and to evaluate the pure effect of HCA on adverse outcome. Our propensity score-matching groups included the known risk factors (age, diabetes mellitus, previous stroke, and hypertension) almost equally, therefore allowing the assumption that the pure effect of use of HCA on postoperative stroke and TND could be evaluated in the current study. Patient-related risk factors, such as older age, diabetes mellitus, and atherosclerosis (peripheral and coronary artery), seemed to determine the operative outcome primarily. Our finding that older age was an independent predictor of TND is consistent with findings reported by Newman and colleagues. ${ }^{19}$

The most important finding was that the duration of HCA did not influence the incidence of TND at all, even in our strictly selected patients, which is inconsistent with findings reported by others. ${ }^{1,2,12}$ In all 3 investigations, the duration of HCA was a significant predictor of stroke or TND both by means of univariate and multivariate analysis. A possible explanation for the difference might be the fact that HCA time exceeded 30 minutes in only $39(14 \%)$ and 40 minutes in only $7(2.6 \%)$ of our patients. In the matched group HCA exceeded 30 minutes in only $8(7.3 \%)$ and 40 minutes in only $2(1.8 \%)$ of 110 patients. In addition, the previous publications ${ }^{1,2,12}$ included patients with acute dissection, which might have influenced the results. Dissection was completely eliminated by the propensity score matching. A propensity score-matching analysis seems necessary under such circumstances to provide a pure evaluation of the influence of variables by excluding selection bias. ${ }^{27,28}$

Increasing experimental and clinical evidence has suggested that the safety limit of HCA might be approximately 30 to 40 minutes at $20^{\circ} \mathrm{C},{ }^{4,11,13}$ whereas others have presumed that this interval might be shorter. ${ }^{29}$ More profound hypothermia to secure more sufficient time for reconstruction will be associated with longer duration of CPB and a higher risk of postoperative bleeding. ${ }^{11}$ The range of HCA of 8 to less than 30 minutes at $18^{\circ} \mathrm{C} \pm 1^{\circ} \mathrm{C}$ in most instances for our patients seems reasonable and still allows some safety margin in cerebral ischemic tolerance. Within this range, the duration of HCA did not affect the incidence of TND at all. This concept seems in agreement with the current individualized methods of brain protection advocated by many experts. ${ }^{4}$
Currently, continuous perfusion to the brain, regardless of antegrade or retrograde status, seems to be preferred by many surgeons over HCA alone. ${ }^{11}$ Nevertheless, we have consistently used HCA for brain protection for several reasons. First, HCA provides a completely bloodless field that allows the surgeon to perform an ideal anastomosis. Second, in ascending aorta-proximal arch replacement, HCA allows for elimination of clamp-compromised tissue. Third, HCA avoids manipulation of aortic arch vessels, such as placement of perfusion catheters, which are routinely used for antegrade brain perfusion and can lead to embolism or intimal injury of aortic arch branches. Finally, HCA is an unquestionably simple and economic adjunct that has facilitated the operation in our hands without increasing operating times. ${ }^{1,12,24}$ When the possibility of embolism of debris from an atheromatous aortic arch is anticipated, a brief period of retrograde cerebral perfusion can be used in combination with HCA, as we did in 6 cases. ${ }^{14}$ Maybe the second and third reason for our choice of HCA would be that no stroke was seen in the $\mathrm{HCA}(+)$ group, whereas 2 $(1.8 \%)$ patients in the $\mathrm{HCA}(-)$ group had stroke in propensity score-matching analysis.

The interpretation of our results must consider inherent limitations of the study. First, the core temperature at which operations were performed was not identical between groups. Normothermic CPB alone is associated with increased blood-brain barrier permeability and thereby brain edema, which can be a possible mechanism of TND. ${ }^{30}$ On the other hand, Plourde and colleagues ${ }^{31}$ demonstrated that temperature during $\mathrm{CPB}\left(28^{\circ} \mathrm{C}\right.$ vs $\left.36^{\circ} \mathrm{C}\right)$ did not influence postoperative cognitive function. Second, the differences in patient distribution between the 2 groups were largely eliminated by a propensity score-matching analysis, but a residual bias might still exist. Third, the current study was not a prospective randomized study but a retrospective nonrandomized study. Thus our results warrant confirmation by larger prospective randomized clinical trials in an ideal setting.

\section{Conclusions}

In a standard clinical setting (HCA of $<30$ minutes and a nasopharyngeal temperature of $<20^{\circ} \mathrm{C}$ ), $\mathrm{HCA}$ does not constitute a significant risk for mortality or neurologic morbidity and appears to be clinically safe. Patient-related risk factors primarily determine clinical outcome.

\section{References}

1. Ergin MA, Galla JD, Lansman SL, Quintana C, Bodian C, Griepp RB. Hypothermic circulatory arrest in operations on the thoracic aorta. Determinants of operative mortality and neurologic outcome. J Thorac Cardiovasc Surg. 1994;107:788-99.

2. Hagl C, Ergin MA, Galla JD, Lansman SL, McCullough JN, Spielvogel D, et al. Neurologic outcome after ascending aorta-aortic arch operations: effect of brain protection technique in high-risk patients. J Thorac Cardiovasc Surg. 2001;121:1107-21. 
3. Eusanio MD, Schepens MA, Morshuis WJ, Di Bartolomeo R, Pierangeli A, Dossche KM. Antegrade selective cerebral perfusion during operations on the thoracic aorta: Factors influencing survival and neurologic outcome in 413 patients. J Thorac Cardiovasc Surg. 2002;124:1080-6.

4. Svensson LG. Antegrade perfusion during suspended animation? J Thorac Cardiovasc Surg. 2002;124:1068-70.

5. Kazui T, Yamashita K, Washiyama N, Terada H, Bashar AH, Suzuki $\mathrm{T}$, et al. Usefulness of antegrade selective cerebral perfusion during aortic arch operations. Ann Thorac Surg. 2002;74(suppl):S1806-9.

6. Peel GK, Stamou SC, Dullum MK, Hill PC, Jablonski KA, Bafi AS, et al. Chronologic distribution of stroke after minimally invasive versus conventional coronary artery bypass. J Am Coll Cardiol. 2004;43: 752-6.

7. Kilo J, Czerny M, Gorlitzer M, Zimpfer D, Baumer H, Wolner E, et al. Cardiopulmonary bypass affects cognitive brain function after coronary artery bypass grafting. Ann Thorac Surg. 2001;72:1926-32.

8. Katz ES, Tunick PA, Rusinek H, Ribakove G, Spencer FC, Kronzon I. Protruding aortic atheromas predict stroke in elderly patients undergoing cardiopulmonary bypass: experience with intraoperative transesophageal echocardiography. J Am Coll Cardiol. 1992;20:70-7.

9. Tovar EA, Campo CD, Borsari A, Webb RP, Dell JR, Weinstein PB. Postoperative management of cerebral air embolism: gas physiology for surgeons. Ann Thorac Surg. 1995;60:1138-42.

10. Schwartz LB, Bridgman AH, Kieffer RW, Wilcox RA, McCann RL, Tawil MP, et al. Asymptomatic carotid artery stenosis and stroke in patients undergoing cardiopulmonary bypass. J Vasc Surg. 1995;21: 146-53.

11. Hagl C, Khaladja N, Karcka M, Kallenbach K, Leyh R, Winterhalter $\mathrm{M}$, et al. Hypothermic circulatory arrest during ascending and aortic arch surgery: the theoretical impact of different cerebral perfusion techniques and other methods of cerebral protection. Eur J Cardiothorac Surg. 2003;24:371-8.

12. Ehrlich MP, Ergin MA, McCullough JN, Lansman SL, Galla JD, Bodian CA, et al. Predictors of adverse outcome and transient neurological dysfunction after ascending aorta/hemiarch replacement. Ann Thorac Surg. 2000;69:1755-63.

13. Griepp RB. Cerebral protection during aortic arch surgery. J Thorac Cardiovasc Surg. 2001;121:425-7.

14. Yerlioglu ME, Wolfe D, Mezrow CK, Weisz DJ, Midulla PS, Zhang $\mathrm{N}$, et al. The effect of retrograde cerebral perfusion after particulate embolization to the brain. J Thorac Cardiovasc Surg. 1995;110: 1470-85.

15. Okita Y, Minatoya K, Tagusari O, Ando M, Nagatsuka K, Kitamura S. Prospective comparative study of brain protection in total aortic arch replacement: deep hypothermic circulatory arrest with retrograde cerebral perfusion or selective antegrade cerebral perfusion. Ann Thorac Surg. 2001;72:72-9.

16. Taylor KM. Brain damage during cardiopulmonary bypass. Ann Thorac Surg. 1998;65(suppl):S20-6.
17. Ahlgren E, Lundqvist A, Nordlund A, Aren C, Rutberg H. Neurocognitive impairment and driving performance after coronary artery bypass surgery. Eur J Cardiothorac Surg. 2003;23:334-40.

18. Reents W, Muellges W, Franke D, Babin-Ebell J, Elert O. Cerebral oxygen saturation assessed by near-infrared spectroscopy during coronary artery bypass grafting and early postoperative cognitive function. Ann Thorac Surg. 2002;74:109-14.

19. Newman MF, Kirchner JL, Phillips-Bute B, Gaver V, Grocott H, Jones $\mathrm{RH}$, et al. Longitudinal assessment of neurocognitive function after coronary-artery bypass surgery. N Engl J Med. 2001;344:395-402.

20. Engelman RM, Pleet AB, Rousou JA, Flack JE 3rd, Deaton DW, Pekow PS, et al. Influence of cardiopulmonary bypass perfusion temperature on neurologic and hematologic function after coronary artery bypass grafting. Ann Thorac Surg. 1999;67:1547-55.

21. Goldsborough MA, Boronicz LM, McKhann GM, Baumgartner WA. Variation in stroke occurrence by cardiac procedure [abstract]. Perfusion. 1997;12:47.

22. Ahlgren E, Aren C. Cerebral dysfunction-a feared complication of cardiac surgery [abstract]. Perfusion. 1997;12:32.

23. Borger MA, Peniston CM, Weisel RD, Rao V, Cohen G, Ivanov J. Perioperative predictors of stroke following coronary bypass surgery [abstract]. Perfusion. 1997;12:36.

24. Eusanio MD, Wesselink RM, Morshuis WJ, Dossche KM, Schepens MA. Deep hypothermic circulatory arrest and antegrade selective cerebral perfusion during ascending aorta-hemiarch replacement: a retrospective comparative study. J Thorac Cardiovasc Surg. 2003;125: 849-54.

25. Hasegawa Y, Ishikawa S, Ohtaki A, Otani Y, Takahashi T, Sato Y, et al. Impaired lung oxygenation in acute aortic dissection. J Cardiovasc Surg (Torino). 1999;40:191-5.

26. Girardi LN, Krieger KH, Lee LY, Mack CA, Tortolani AJ, Isom OW. Management strategies for type A dissection complicated by peripheral vascular malperfusion. Ann Thorac Surg. 2004;77:1309-14.

27. D'Agostino RB Jr. Propensity score methods for bias reduction in the comparison of a treatment to a non-randomized control group. Stat Med. 1998;17:2265-81.

28. Blackstone EH. Comparing apples and oranges. J Thorac Cardiovasc Surg. 2002;123:8-15.

29. McCullough JN, Zhang N, Reich DL, Juvonen TS, Klein JJ, Spielvogel D, et al. Cerebral metabolic suppression during hypothermic circulatory arrest in humans. Ann Thorac Surg. 1999;67:1895-9.

30. Harris DN, Bailey SM, Smith PL, Taylor KM, Oatridge A, Bydder GM. Brain swelling in first hour after coronary artery bypass surgery. Lancet. 1993;342:586-7.

31. Plourde G, Leduc AS, Morin JE, DeVarennes B, Latter D, Symes J, et al. Temperature during cardiopulmonary bypass for coronary artery operations does not influence postoperative cognitive function: a prospective, randomized trial. J Thorac Cardiovasc Surg. 1997;114:123-8. 